\title{
The Image of the Hyper City
}

\author{
Davide Landi ${ }^{1}[$
}

Published online: 29 September 2018

(c) The Author(s) 2018

\begin{abstract}
Since the nineteenth and twentieth century, information has been pivotal both in the cultural tradition and then in the economic tradition. While the Fordism economic model and its specialisation requirements originated a simplistic zoning and single-use development approach to the design of a city. It, however, determined a fragmented growth of cities. Inevitably, the zoning as an urban strategy affected the architectural scale. Nevertheless, the idea of information, commercial goods and thereby people freely able to flow through the city allowed architects and urban designer to conceive new types of urban infrastructures. For example, trains, which were designed on the model of urban "arteries and veins." Over time, the persistence of urban and architectural segmentation has strengthened social and economic inequalities among urban society. In addition, information has played a more vital role in this strengthening process. The technological achievements of the twentyfirst century such as information technologies have significantly affected cities. The new informational patterns have provided new ways of designing, and in turn how societies experience cities. These "quantified cities" consist of digital data that dynamically interacts with "quantified human beings." Consequently, a renewed urban semiotics is established, which is built around an alternate sociological comprehension. Is this new urban semiotics able to heal an ill and divided urban body? The paper will investigate a new concept of "quantified city" based on the notion of "Hyper-Reality," and its inhabitants who are entering in a "post-human" condition while living in a dynamic urban environment. In particular, the critical analysis will be used as a "tool" for redefining the perception of the city (i.e., the image of the Hyper City) through inhabitants' (post-humans') relational patterns which are technologically mediated (i.e., Google Maps, Uber, Instagram, etc.). The more traditional notion of urbanisation is questioned with a focus on how the an urban society is embedded within the digital condition and the notion of a city.
\end{abstract}

Keywords Hyper reality · Augmented reality · Post human · Network society · Urban design - Information technology

Davide Landi

D.Landi@2016.ljmu.ac.uk

Extended author information available on the last page of the article 


\section{Introduction}

The twentieth century Fordism model was underpinned by the necessity of economic performance and efficiency [7, 34]. Historically, the term 'Fordism' has been used to describe the modern economic model, which supported mass production and consumption. Over time, the Fordism model and its economic activities determined a diversified growth of cities [26]. However, it was a compartmentalised diversification, and thereby the city acquired a functional and spatial differentiation. This sanctioned the beginning of a naïve zoning and single-use development [25, 40, 55]. Nowadays, this urban fragmentation still prevails. Inevitably, it has strengthened social and economic inequalities among its inhabitants [7].

Furthermore, the 2008 economic crash stated a failure of traditional economic models [50] while the contemporary culture has posed profoundly different challenges. The term 'culture' refers to all the conscious and unself-conscious agents and challenges, which are latent in the contemporary conditions (e.g., new technologies). For example, the advent of information technology (IT) [e.g., Internet and the more recent Internet of Things (IoT)] have redefined the availability work and nature of everyday life [52]. This has had consequences also on the nature of human beings. As noted by authors like Claudel and Ratti [12] and Hayles [23], it also affected the physical and psychological functioning of human beings. Within this the term "post-human' identifies this transition in human nature. Considering these as the latest stages of the two "generative dimensions" of cities, the "social and economic dimension" have entirely new structures [30, p. 22]. This confirms the urgent necessity of new urban strategies. Inevitably, they have implications, which concern not only the spatial organisation but also the social organisation of cities [21].

In this exploratory article, I examine the Hyper City. The Hyper City is a term adopted in this article, which envisions a possible future phase of contemporary urban systems. In particular, The Hyper City synthesises the application of the "Hyper Reality" technology to the physical, existing urban environments. The "Hyper Reality" is a technology yet part of an ongoing research project whose author showed for the first time in a 2016 concept film [42, 44]. Nevertheless, it provocatively overlaps physical and virtual settings while combines existing technologies such as Virtual Reality (VR), Augmented Reality (AR), Wearables, and the Internet of Things (IoT) [44, 45]. This substantially alters how we perceive the built environment beyond already known notions such as the "Senseable City," the "City of Bits" and the "Informational City." It is necessary here to clarify exactly what these notions mean. First, the "Senseable City" is a notion suggested by Carlo Ratti [12] who saw the city as a "real-time system." The growing number of wearable electronic devices (e.g., smartphones) generates data that allows researchers, urban designers, and architects to comprehend and thereby to design the built environment. Second, the "City of Bits" is a notion proposed by William J. Mitchell who attempted the introduction of a city deeply transformed by the technological revolution (i.e., digitalisation of the telecommunications, the ongoing miniaturisation of electronics, etc.). It also refers to the capacity of using specific knowledge of data and information management in which doers and users potentially overlap [47]. 
Third, the "Informational City" is a notion coined by Castells [9] to bind the changes in information technologies with the spatial dynamics.

This paper represents a partial insight into this subject, aiming to critically analyse how the "Hyper Reality" [44] may influence the perception of the city by its inhabitants. Fundamental, it is to consider also the possible effects of the Hyper City on the relational patterns of its "post-human" inhabitants. The first section of this paper, therefore, provides a historical insight into the technological revolution of the twentieth and twenty-first century to the advent of the "Network Society." According to Castells [10], the "Network Society" is the term, which summarises cultural, political, social, and economic changes caused by the spread of information technologies and their networked structures. The remaining part of this section considers the rise of the "post-human" and its key aspects. While the second section lays out the elements that compose the image of the Hyper City, focusing on four key themes: Scale, Form, Time, and Materiality.

From this, it follows, to anticipate the paper's conclusions, the Hyper City envisions a possible transformation of the urbs, its perception, and its civitas [58]. The "Hyper Reality" is a visionary example of an urban strategy, which has major consequences on design theories and practices as well as the whole experience of the built environment by its occupants. On the one hand, urban design and architectural theories and practices are not anymore limited by three-dimensional Euclidian geometry constructions. Consequently, urban designers and architects are required to propose "situations." This term refers to the definition first suggested by Picon [56] who distilled it from Karl Friedrich Schinkel's representation of Altes Museum in Berlin. Here, the architecture only sets the stage on which events such as education and friendship occur. On the other hand, this can be translated into challenges (i.e., sensorial deprivation, preservation of cultural values) for an "urban society" [34, p. 1] in the digital condition. The term "urban society" will be used in this paper to refer to the Lefebvrian idea of total urbanisation not limited to the built environment [34]. However, this transformation will take place only through the acknowledgement of a renewed urban semiotics. While the "post-human" inhabitants must assimilate the ability to interpret it. Only then, the contemporary city becomes the potential container in which this re-organisation will heal a fragmented urban body.

\section{The Emancipation of the "Post-Human" in the "Network Society"}

Cities are complex by nature. They are places of buildings and people [28]. In ancient time, Romans identified these two entities as the urbs and the civitas. Inevitably, this established a contradiction between the distinction of two entities and their indissoluble union. The complexity of rituals, emotions, convictions and businesses have given form to cities [58]. In this vein, Castells [8] extend this union to the urban semiotic. In one of the sections of his book The Urban Question, the author criticises Lynch's work on the image of the city [38]. In particular, Castells underlines a paradox between Lynch's logic design approach and his analysis, which was underpinned by a robust social meaning. 
Consequently, it is impossible to inform the semiotics of space without considering its sociological comprehension [8]. In light of recent changes in the information technology and the nature of human life, it is not possible to ignore the necessity of questioning this union again. Nevertheless, the context in which these changes have occurred need to be more comprehensively illustrated. Therefore, the following section is organised into two paragraphs. The first part untangles the historical and social development of the information technology such as the Internet. The remaining portion reveals its repercussions on the human nature. Consequently, the "Network Society" [10] and the "Post Human" [23] are outlined. The emerging argumentation constitutes a robust background supporting my discussion surrounding the rise of a renewed urban semiotics.

\subsection{A Brief History of the Internet, the "Network Society" and the "Post-Human"}

The twentieth century focus on information (i.e., mass media) and their circulation rather than people and products made possible the development of a new generation of technologies such as the computer $[10,17]$. One of the first examples of large calculators was the Electronic Numerical Integrator and Computer (ENIAC), a tabulating machine. It was used in the Second World War for the H-Bomb computation [17]. While historians and theorists of architecture like Picon [17] conventionally recognise the first consequence of this interest on information in the Buffalo Prudential Insurance Company Offices (1894-1895) designed by Sullivan and Adler [13]. The data, their processing and communication became central in industry, after in everyday life [21]. This led to one of the essential technological revolution of the recent history: the internet.

On the 29th October 1969 at 10.30 PM, therefore, a group of researchers at the University of California, Los Angeles broadcast the first message. The first node of the internet was created [37]. The internet became the tool for an accelerated and profoundly changed society, which has been structured around a paradoxical opposition [10,33]. On the one hand, the rise of a global economy that followed the modern capitalism and the Fordism model has promoted free flows of goods, wealth, knowledge and power. Over time, this has requested a more flexible economic model in which companies could easily to decentralise themselves as well as network. On the other hand, the cult of the individualism, the social groups' withdrawal and avoidance patterns started in the nineteenth century has prevailed. This has strengthened the physical and social fragmentation phenomena initiated during the Fordism era. The internet, therefore, was conceived to fill this gap [10, 34].

Castells [11], p. 469] defined this radically transformed society as the "Network Society," and the internet has been its backbone. Besides the new information technology paradigm, it has opened the way to new cultures such as the "real virtuality," [10, p. 331], new economies such as telebanking, teleducation, telecare and their related institutions and services $[10,11]$. In more recent years, Mitchell attempted to embody these new cultures and economies in new types of cities $[1,10]$. Nevertheless, the structure of networks and its peculiar elements such as nodes and their multiple forms have imposed a new organisational logic. It has not been linked to the 
conventional notions of space and time [10, 11]. Space has been dissociated from its physical dimension and the necessity of spatial proximity in everyday activities. While time has been dissociated from its biological evolution that characterises events of the physical world. Consequently, this has determined a new morphology of society $[10,11]$ and the built environment $[47,48]$.

While urban and social theorists have attributed different names to this phase of the built environment such as the "Senseable City" [12], the "City of Bits" [47] and "Informational City" [9]. They present common features. For example, all of them have considered the adoption of mainly non-physical/digital infrastructures for the collection, circulation and computation of information. In this, the physical space and society have been indissolubly conceived with their digital shadow [12, 47]. The "bandwidth," therefore, determines the performance of these new types of cities [48, p. 103]. According to Mitchell [47, 48] principles such as "soft transformation" and "dematerialisation" have affected the design of space. Its appropriation and experience are unequivocally altered [48, p. 147]. The "City of Bits," for instance, has preserved many conventional architectural elements, while inserting new ones such as electronic hardware, access points to networks and sensors for data collection [47]. Additionally, some old activities and functions have been removed or simply redistributed while new one added in it. Informationally, digitally, and virtually permeated neighbourhoods have been containers of people who dwell, live and work in them. Therefore, this has deeply modified the act of social grouping and interacting. It does not necessarily require physical spaces because some of them have been relocated in virtual settings- "gathering place on the fly" [48, 50, p. 91]. Consequently, the proliferation of networks, the global hyper-connectivity, and thereby the new notions of space and, time have had repercussions on the city and human life [49].

Nowadays, material patterns have become less relevant than informational ones; the fusion between biological and machine entities has started. Human beings do not only integrate them into their every day as an essential rather than an extra asset; they are also more digitally aware. This has generated the augmented digital body $[12,47]$. It is, therefore, a network and at the same time, a node storing and sharing information [48, 49]. Commenting on this, Qohen Leth, the main character of Terry Gilliam's film-The Zero Theorem, says: "We are connected through fibre optics and memory chips" [68]. This allows smartphones and watchbands to receive and transmit constantly data. Together with clothes and other everyday accessories digitally connect individuals and their parts [49]. Additionally, audio and video sensors embedded in human bodies partially aid those who are sensory impaired. In the near future, external devices both electronic and digital compensate the biological decay of neurones that usually happens with the ageing process. Consequently, the brain preserves its mental capacity by "outsourcing more mental functions" [49, p. 34]. The 1995 film Johnny Mnemonic envisioned this possibility in a dystopian future. While the data storage implanted in his brain allows Johnny to carry sensitive information. It cost the main character the lost of his childhood memories [27].

Nevertheless, this is just the later stage of the mechanisation and quantification of people started in the nineteenth century with Francis Galton's studies on fingerprints and their record [17]. Gordon Bell later investigated it with his project "Your Life, Uploaded." The computer scientist recorded and stored personal data such as 
biometrics, everyday photos, and computer activities in a specially designed hardware and software from more than 10 years. The project, therefore, generated data set ready to be shared with his family, and a more extensive network [12, p. 50].

Several publications have described these ongoing transformations in human life and its nature. In the book How We Became Post Human: Virtual Bodies in Cybernetics, Literature, and Informatics [23], Hayles identified four indicative principles. The "post-human" recognises other individuals as a complete merger between the flesh and intelligent machines. Consequently, the "post-human" perceives artificial additions to the human body as a natural continuation of the evolutionary process. The informational consistency of the "post-human" prevails on the biological one [23]. This reveals similarities with the "body phantom" condition, which describes a person's capability to integrate him/herself with various objects (i.e., technology) $[16$, p. 35]. The "post-human," thereby, considers the notion of identity not as primary but as a secondary factor, that characterises individuals. The "post-human" is a computing machine able to elaborate data. The historical division between the physical body and "virtual body" [23, p. 20], and genders are obsolete [16, 23]. The physical body engages a symbiotic relationship with the machine while experiences its dematerialisation, as the built environment [23].

The "Network Society" [10] and the technological revolution have forced the human condition towards the "post-human" [23] condition. "I am visible to Google (C. I link; therefore I am" [49, p. 62]. Technology and data are no longer as a prosthetic limb. They merge, thereby, with the human body [12]. Picon [56] described this process as a co-production process. It takes place both in the physical and the virtual domain through the contribution of different figures not necessarily human. Inevitably, it informs an alternate relationship between the built environment and "post-human" subjectivity [16]. An implication of this, thereby, lies in the possibility of tracing the ethical borders of the described merging process.

\section{What is "Hyper City"?}

The contemporary urban landscape is the outcome of a capitalist economic model. Inevitably, this has emphasised the visual experience of the urban landscape. Considering this, in the seminal book The Eyes of the Skin. Architecture and the Senses, Pallasmaa writes: "The contemporary city is the city of the eye" [54, p. 33]. Constructed examples such as Kabukicho, Tokyo (Japan) and Las Vegas (USA) confirm this tendency. In particular, Las Vegas, as argued by Venturi and Scott Brown [69], presents a pre-eminence of signs over the space, of communication over space [39].

Furthermore, the recent dramatic changes in information technology (IT), as well as the new economic scenario following the 2008 economic crash, have had profound implications on architecture and urbanism, and their spatial language [9, 17]. This has also reframed the experience of the built environment by its inhabitants. The contemporary city is not just a simple construction of three-dimensional physical paths and nodes (i.e., transport links), districts and edges (i.e., urban territories), and landmarks (i.e., buildings) [21, 38]. It is, therefore, no longer coherent with past urban artefacts as investigated by urban theorists and historians such as 
Kevin Lynch, Jane Jacobs, Spiro Kostof, and Manfredo Tafuri. The contemporary city functions differently [48]. At a time when the glassy screens of technological devices seem not to be any more the only boundaries between virtual and real space, the Hyper City embodies the possible imminent next phase of the city [16]_Fig. 1.

Nevertheless, what are the elements that identify the Hyper City as a possible future urban strategy? Is this the next stage of the urban semiotics? This section first gives critical insight into the Hyper City and thereby of the "Hyper Reality" technology [44]. It defines the Hyper City's peculiar elements characterising its image.

\subsection{The Hyper City Image and Its Elements}

Over time, a city can embody a "public image" as well as multiple individual images subject to its occupants' experience [38, p. 46]. By combining the physical elements of the city and its sociological comprehension respectively, it is possible to distillate the image of the city. Nevertheless, the Hyper City has its elements, which are not necessarily physical. This section illustrates them as a contribution to the definition of the Hyper City image.

\subsection{Scale}

Historically, the notion of scale attempts to provide an organisational framework, which facilitates the comprehension of the world and human activities (i.e., the household scale, the community scale, the nation scale) [20]. In architecture and urbanism, the scale is the measuring element that defines the relationship between the built environment and the human body [22, 63]. Nevertheless, the new socio-economic and political situation and technological revolution refined and

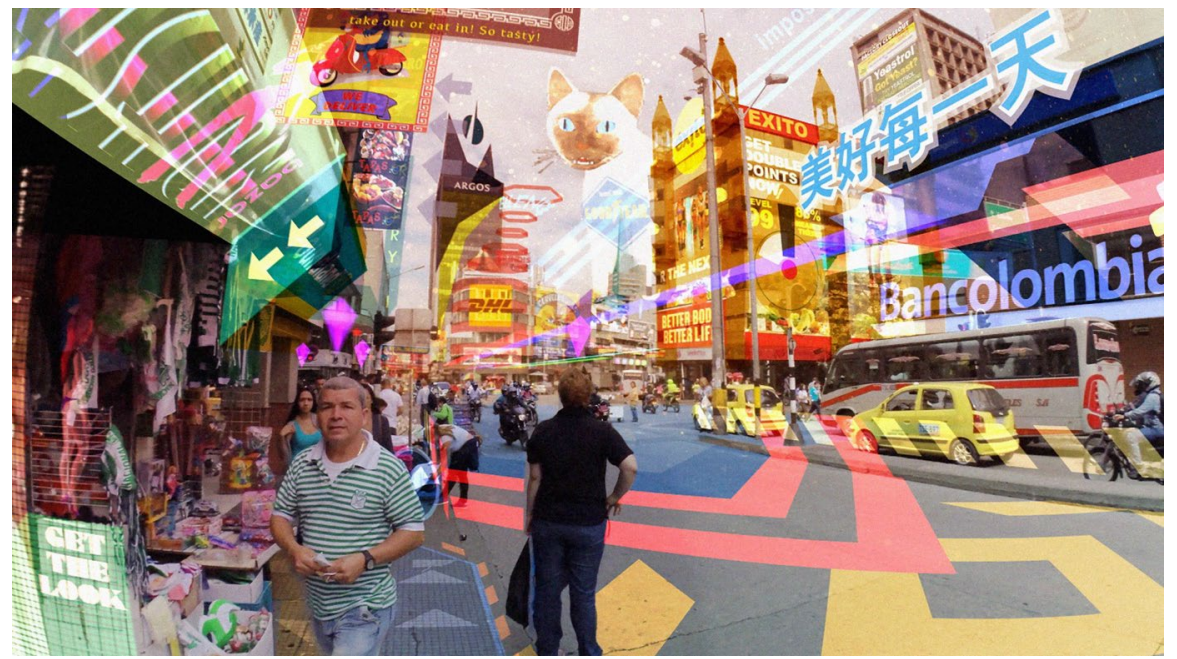

Fig. 1 The hyper city street view. Source: Matsuda [44] 
restructured the scale framework [20]. First, three different scales are characterising the technological devices, which embodies the merging boundaries between virtual and real space: the "screen places" [48, p. 33]. Wearables such as wristwatches, Google Glasses@ $\subseteq$, for example, represent the smallest scale. Screens such as laptops, PC constitutes the intermediate scale. Virtual and physical urban billboards compose the biggest scale [3, 48]. Second, colours and textures identify objects inside the "screen places" (e.g., Google Maps@). While the "zoom in and zoom out" gesture, thereby, address a hierarchical organisation of spaces inside the "screen places" [56]. The Hyper City combines these three aspects [49, 50]. The "screen places," the use of colours and textures and the "zoom in and zoom out" gesture converge the users' attention on a specific portion of the Hyper City. Therefore, the organisational function of the scale loses its historical significance and what is outside a screen is marginal [17]. Apps for smartphones such as Yelp are premonitory examples. "It generates an unstable focus" [17] that affects the conventional notion of proximity and distances. The Hyper City as the strip in Las Vegas is simultaneously close and distant [69].

\subsection{Form}

Vitruvius [71] introduced the notion of "ornament" as a meticulous arrangement of discrete elements, which give "order" to a building. The "ornament" and the "order" of buildings and thereby of cities affect their visual quality and "legibility" [38, p. 2]. The term form, therefore, identifies in this paper these discrete elements, which coherently contributes to the simultaneous composition of buildings, cities and their image. Over time, citizens have perceived this image as almost static entities while buildings and in particular cities are a temporary construction of space [30, 38]. The technologically permeated socio-economic and political scenario just demanded architectural and urban forms that were more dynamic. Consequently, the Vitruvian order made the way to a programming order $[48,66]$. For example, Hyper City combines physical and virtual elements such as real shopping windows with virtual advertisements. The private and public space is informed by codes [41, 48]. On the one hand, this is in line with the ephemeral nature of the built environment. On the other, the built environment continuously change their legibility. The "ornament" [71] becomes a tool for the fulfilment of clients' requirements [17, 56]. Therefore, the architectural and urban spaces accommodate virtual narratives, which serve who control them [49]. Concerning on this, films such as Minority Report [46] and The Zero Theorem [68] offer many examples (i.e., a customised advertisement that follows citizens along urban streets). Consequently, space acquires ambiguous reliability in which these elements become simple signs or decorations of the Hyper City $[56,66]$. Inevitably, they generate a tension between the public image and the multiple individual images of the Hyper City [48]. Respectively, the ensemble of virtual and digital elements is at the same time tautological for masses while essential for individuals. This defines a fracture between traditional architecture and urban forms, and a form, which is a consequence of an event [17]. 


\subsection{Time}

Over the past centuries, the experience of the city has been subject to a dramatic acceleration. Parallel to this acceleration, Castells [9, p. 461] characterised the time of the contemporary city and the network society which inhabits it with the notions of "simultaneity" and "timelessness." Mitchell [47] described the time of pre and post network society respectively as "synchronous" and "asynchronous." By embedding the discontinuity of the bits $0-1$, events are fragmented in terms of both space and biological time [47, 48]. The Hyper City [43, 44] embodies these two notions into the everyday experience of its inhabitants. Citizens, for instance, simultaneously combine activities such as doing the shopping while taking care of virtual pets. They can share instantaneously their activities, "Loyalty Points" [43] and "Social Credits" $[1,4]$ as a medium for bringing people together according to their interests and points/credits. Furthermore, citizens can take the bus while gaming and video are calling their "inspiration guru" [44]. On the one hand, this produces a sense of immediacy. On the other hand, this "timelessness" produces a certain detachment from the biological passage of time [9]. Consequently, the Hyper City itself loses the "gradient of time and memories." For example, there are no "digital ruins" that narrate its dissolution or "layering process" [29, p. 250; 70]. Nevertheless, this stresses Lefebvre's analysis of urban rhythms [35]. Lefebvre defined the rhythm as the interaction between physical energy consumption, space and time [35]. According to his analysis, the advent of the capitalist economic model profoundly affected his notion of rhythm. It determined a shift from the "natural and creative" rhythm to a "rhythm of production" [35, p. 64]. The digitally and networks mediated city questions this analysis again. The Hyper City proposes a juxtaposition of alternate rhythms. Citizens, therefore, experience and perform different rhythms depending on the network of which they are part. This reveals a paradox between the body and environment's physical limits, the speed of the bits, and a detached coexistence of multiple rhythms [49].

\subsection{Materiality}

The materiality of the Hyper City results from the combination of matter, time and the action of its inhabitants. Consequently, this new materiality redefines the relationship between the "post-human" inhabitants [23] and the matter [56]. While the time becomes the hinge element in this relationship. Historically, the matter has functioned as human beings' sensorial stimulator (i.e., the sight and the touch). The recent acceleration of urban experiences in which multiple rhythms coexist generated a "post-human" necessity towards overstimulation. This is something started in the recent past through the adoption of technological platforms. For example, global digital and physical platforms such as iTunes@ and iPhone $(C)$ have generated tailored and portable overstimulating setting for their clients $[17,56]$. However, The Hyper City materiality [45] embraces this need for a psychological more than physical overstimulation, and thereby it proposes overstimulating everyday urban and 
architectural settings according to inhabitants' interests and routines. The giant virtual cat, billboards, signs on sidewalks and roads, for instance, are just a few of the multiple scenarios that the Hyper City can offer. While virtual interactive diallers, keyboards and screens introduce a new tactile experience [44, 46]. Inevitably, the overstimulating urban and architectural environments become assisted settings. For example, cooking is supported by online recipes, which are virtually accessible [41]. In this, the Hyper City merges virtual and physical domains in which information and bits inform an alternate matter. It together with time and the action of "posthuman" inhabitants make the Hyper City materiality. Questionable, although, is the threshold between physical and virtual stimulation.

\section{The Challenge of the Hyper City: Redefining the Urban Society in the Digital Condition}

Previous sections outlined that the advent of technology and the rise of the internet are rooted in a more in-depth and long-standing necessity [17]. While the Hyper City's elements (i.e., Form, Time, Materiality, and Scale) frame its image. The "post-human" condition exemplifies the cultural context in which the Hyper City image might be fully understood. This, therefore, may establish the framework for a renewed urban semiotics. Historians and theorists of urbanism and architecture have defined it as "tectonic" $[17,56]$. However, the Hyper City may pose some challenges which concern with the notion of inhabitation and urbanisation [16]. Design disciplines and practices are inevitably affected.

Nowadays, the majority of the global population live in cities [7]. Consequently, it is possible to assume that the society is going through a process of complete urbanisation: the urban society [39]. On the one hand, it has informed real urban spaces, which have embodied social, political and economic dynamics. On the other hand, these same real urban spaces have addressed social, political and economic dynamics [29, 33]. This has established a reciprocal relationship between different dynamics and the built environment. Unequivocally, inhabitants are subject to this relationship [50]. Nevertheless, the Hyper City questions this more conventional idea of urbanisation and urban transformation. It is an alternate process of complete urbanisation, which is far beyond the making of physi$\mathrm{cal} / \mathrm{real}$ space, and the passage of biological time. This is an urban society in the digital condition. For example, the juxtaposition of different rhythms, multiple forms and orders inevitably modify the long-standing capacity of bringing different people together $[33,65]$. The multiple individual images of the Hyper City emphasise a subjectification of the urban environment started with the Fordism model [33]. Even if networks might overtake segregation boundaries due to physical factors such as distances and biological time, the separation of individuals in same places is strengthened [50,62]. This is an individualistic detachment, which is already latent in our contemporaneity [18, 63]. The Hyper City inhabitants, for instance, are globally connected through their technological bubbles while detached from their immediate surroundings. Only when one own technological bubble burst, the immediate surroundings and their inhabitants reveal themselves 
[41, 44]. Consequently, the real urban spaces may lose part of their potential equalising and educational function. The unexpected is not synonymous with a positive displacement and thereby growth, although it is an equivalent of risks. This way in which the real urban space may be regulated is opposite to how was argued extensively by authors such as Richard Sennett and Henri Lefebvre [34, $59,62]$. The hacker who steals the digital identity of the Hyper City citizens is an example [44]. It inevitably affects the notions of looseness and "social time," which are peculiar to real urban spaces $[14,33$, p. 172]. The conventional participation and appropriation of real urban spaces, therefore, is inevitably altered. Nevertheless, they match with avoidance patterns, a necessity for "coherent identity," which are rooted in the human being by nature [57, p. 66]. Historically, it may have parallels with the notion of "multiple cities" or "dual city" [29, p. 25; 48, p. 81]. By embodying Virtual Reality (VR) and Augmented Reality (AR), however, the Hyper City becomes a shelter from, and a test for the physical reality and its possible uncertainty [44]. This also is coherent with one of the visions of a forthcoming future suggested by Black $[1,2]$. The television series showed in the episode Hang the DJ that how VR may be a simulation/testing tool for an online dating app.

Surprisingly, this is not far from what is already happening in countries such as China. The Chinese "Social Credit System," [4] for example, has been the first step towards this scenario. The social score determines the interaction between the inhabitants (i.e., professional careers development and access to services), and thereby it conditions their behaviours [1,67]. Additionally, the constant presence of technology (i.e., augmented reality and wearables) introduce an additional layer of distortion in human being's behaviours and thereby relations. The increasing use of "Screens, Electronic Audio, and Text Narratives" proposes an alternate way of interaction $[49$, p. $109 ; 68]$. While it is more coherent with the

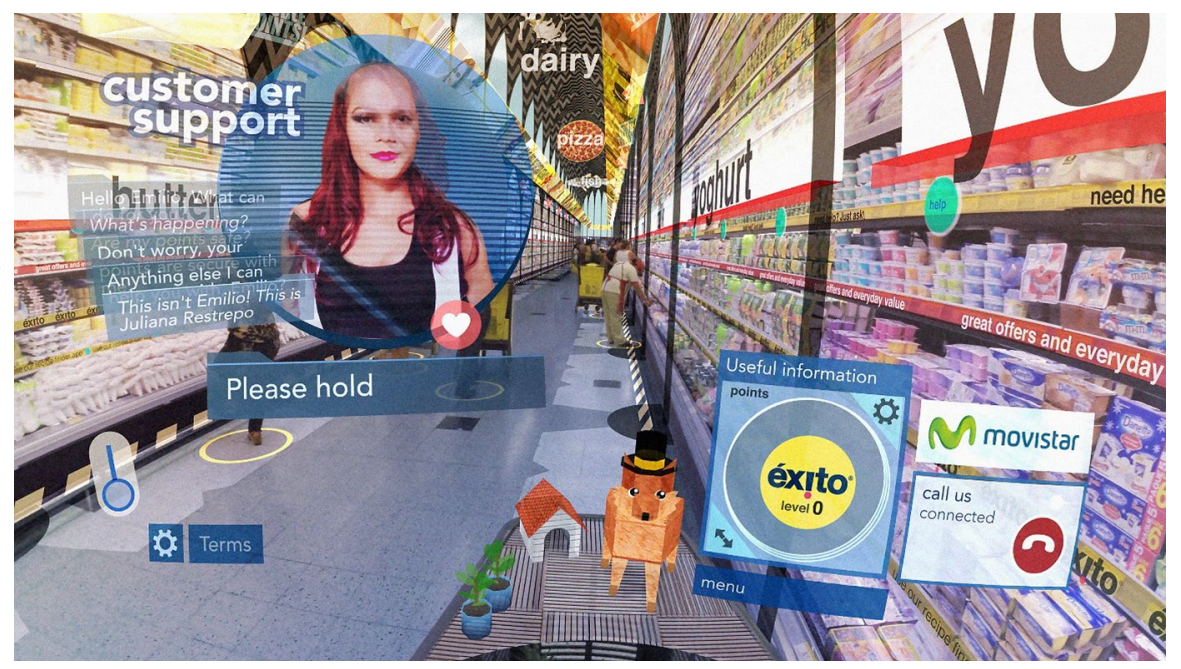

Fig. 2 The hyper city shopping arcade. Source: Matsuda [44] 
"post-human" expectations for interrelation patterns. This was also forewarned by authors such as Zamyatin [72], Orwell [53] and Gilliam [5], who imagined a dystopian future in which control prevails over action-Fig. 2.

Consequently, people' notion of public and private identity mutates. It is not limited to physical thresholds, although it also concerns virtual spaces [16, 49]. Tools such as sensors, security cameras, webcams, GPS systems and smartphones collect and manage 24-h a day people's data and information. The boundaries of different realms: public, private, physical and virtual, inevitably blur. Electronic identities and IP addresses together with more recent devices such as the "data box" become guarantors of people's online privacy and balance between these diverse realms [12, 48]. However, some hazards are implied. It exposes people to "not only physical hijacking but also to virtual hacking." [47, 49, p. 6]. Generally, virtual hacking operates in the virtual domain with direct repercussions on the physical/real one. These repercussions may have different and unexpected epilogues. For example, virtual hacking may become an act of social justice against paedophilia [1]; while also being a violating act of domestic privacy and grief such as occurred with the "Catsouras Family" [37]. Consequently, the withdrawal from the public life paradigm, which started with the modern capitalism [31, 61], requires an additional gesture not necessarily sufficient: to turn off network connections.

All of these aspects correlate with a dependent necessity in being always connected to perform as "post-humans." A careful balance in accessing to networks and the virtual realm may limit what may become an unhealthy obsession [16] instead. Individuals may lose their ability in differentiating the public and the private, the physical and the virtual spheres [1,68]. Inevitably, this ambiguity is also reflected in human beings' decisional roles and responsibilities [47]. Films such as Her [24] and Nirvana [51] exemplify this tendency. Operative Systems (OS), and virtual characters who have sentience and can evolve may turn human beings into passive recipients [70]. Therefore, the human part may be the weakest in the "post-human" condition [31]. The rising number of centres for internet addiction [37], as well as the constant religious references in the virtual realm, confirms this. The virtual votive niche in the Hyper City settings, for instance, is a purifying and healing place from malicious software [44]; while the creation of a virtual paradise, "San Junipero," alludes to a human incompleteness [59] and ancient need for an eternal afterlife [1].

These arguments are likely to be related to a contradictory sensorial capability of the "post-human" [23]. The contradiction lies in the fact that "post-humans" [23] ask for overstimulating settings, while the adoption of smart devices and intelligent/ assisted environments simplifies their sensorial and intellectual activities (i.e., pinpoint the actual position on a digital map) [20, 49]. This frames a context in which the abstract is not anymore subject to speculative and imaginative freedom. This may saturate a sensorial independency, which has belonged to human beings since ancient time [64]. Additionally, the easy access to information enhances individuals' knowledge, while inhibits their values and thereby individuals' action [31]. Sennett $[19,63$, p. 166] described this context as "systems of prescription" with a reductive, deskilling and stupefying effect on its inhabitants.

The present analysis is significant in another one major respect. Architecture and urbanism as professions and disciplines are radically affected in this scenario. 
Besides the preparation of plans, and forms mainly through the use of codes, and data [47, 48], architects and urban designers should create "situations" which also inform time, materiality and scale of the Hyper City [16, 56]. These "situations" recombine virtual and physical elements [47]. In this, people may become active contributors by making available their own digital data. For example, people may share an apartment as well as vehicles in "situations" provided by designers [12, 63]. In a certain sense, designers in collaboration with inhabitants digitally hack a fragmented urban body. Only then, the Hyper City may generate places for engagement, which overtakes overstimulating individualistic experiences and functional differentiation [47, 49]. It is possible, therefore, to preserve the architectural and urban design profession from an excessive "technicization of the every day" due to the availability of a broad spectrum of digital and analogical design tools [70, p. 18].

\section{Conclusion}

The present paper showed how the rise of information technology, networks, the internet and their effects on society (i.e., "post-human" condition) were historically linked to the nineteenth and twentieth century interest towards information, in particular, commercial information and their complex inter-relationship with cultural traditions. From this, the article identified the "Hyper Reality" as a future urban strategy. This is possible through the acknowledgement of renewed urban semiotics and its sociological comprehension. The tools for the sociological comprehension of the Hyper City are its elements (i.e., scale; form; time; and materiality). These constitute an alternate language, which frames its image. Therefore, this image is not limited to a series of precise physical and virtual elements, although it is inseparable from its "post-human observers" [8]. On the one hand, they are coherent with some of the post human's characterising aspects. On the other hand, this renewed language and thereby image embed some risks. First, the Hyper City has a virtual impact on existing, physical urban settings. It superimposes computer graphics on the physical city [48]. The changes, therefore, may be more apparent and superficial than real [33]. Second, this may produce a redundant "noise" that may alter and confuse the semiotics of the city [31, p. 600]. In extreme cases, the merging of the actual, the real, with the possible and the virtual may determine a loss of meaning of the elements [56, 70]. Additionally, the strong subjectification of the city facilitates the control of the inhabitants [50] who become customers of a city and reject their collective responsibilities [65].

Consequently, designers are responsible for proposing "situations" as a medium for actual changes. By a specific and balanced containment of the virtual impact on the real world and a careful use of the Hyper City elements, architects and urban designers produce a space that communicates a renewed order and its related meaning [70]. It rejects the analogy with Venturi and Scott Brown's visual symbolism [69] while embraces diverse urban semiotics underpinned by a heterogeneous social time, and social space [36]. This may make the Hyper City dialogic which can promote growth and knowledge [6, 15]. Ensuring this, the Hyper City becomes the "city of thresholds", which limits individual bubbles, routines and boundaries while 
fosters alternate social groups and behaviours [14, p. 173; 60]. The act of technological "domination," therefore, is counterbalanced by the act of inhabitants' "appropriation" [11, 32, p. 166]. The "Hyper Reality" as future urban strategy coordinates new synergies crossing different spheres (i.e., different practitioners, inhabitants and policymakers) which reconcile a fragmented and ill urbs, with a civitas who is entering in the "post-human" condition $[6,63]$.

Acknowledgements Dr. Emma Roberts (LJMU); Dr. Grahame Smith (LJMU).

Open Access This article is distributed under the terms of the Creative Commons Attribution 4.0 International License (http://creativecommons.org/licenses/by/4.0/), which permits unrestricted use, distribution, and reproduction in any medium, provided you give appropriate credit to the original author(s) and the source, provide a link to the Creative Commons license, and indicate if changes were made.

\section{References}

1. Black, Mirror. 2016. Series, season 3. Los Gatos, CA: Netflix.

2. Black, Mirror. 2017. Series, season 4. Los Gatos, CA: Netflix.

3. Blade, Runner. 1985. Film. Directed by Ridley Scott. USA: The Ladd Company, Sir Run Run Shaw, Tandem Productions, 117 mins.

4. Botsman, R. 2017. Big data meets big brother as China moves to rate its citizens. WIRED. Available at http://www.wired.co.uk/article/chinese-government-social-credit-score-privacy-invasion Accessed 8th December 2017.

5. Brazil. 1985. Film. Directed by Terry Gilliam. USA-UK: Embassy International Pictures, 142 mins.

6. Brenner, N., P. Marcouse, and M. Mayer (eds.). 2012. Cities for people not for profit. London: Routledge.

7. Burdett, R., and D. Sudjic. 2008. The endless city. London: Phaidon.

8. Castells, M. 1977. The urban question. A marxist approach. London: Edward Arnold.

9. Castells, M. 1991. The informational city: Economic restructuring and urban development. Oxford: Wiley-Blackwell.

10. Castells, M. 2000. The rise of the network society. Oxford: Wiley-Blackwell.

11. Castells, M. 2012. Changing the world in the network society. In Networks of outrage and hope, ed. M. Castells, 246-271. Cambridge: Polity Press.

12. Claudel, M., and C. Ratti. 2016. The city of tomorrow: Sensors, networks, hackers, and the future of urban life (the future series). New Haven, MA: Yale University Press.

13. Curtis, W.J. 2009. Modern architecture since 1900. London: Phaidon.

14. Franck, K.A., and Q. Stevens (eds.). 2007. Loose space: Possibility and diversity in urban life. London: Routledge.

15. Frampton, K. 2007. Modern architecture: A critical history. London: Thames \& Hudson.

16. Grosz, E. 2001. Architecture from the outside: Essays on the virtual and real space. Cambridge, MA: MIT Press.

17. GSD Harvard. 2013. Online video. Antoine Picon: Digital Culture in Architecture. Available at https:// www.youtube.com/watch?v=ytTpwTtoo6g. Accessed 2 May 2018.

18. GSD Harvard. 2016. Online video. Richard Sennett: The Open City. Available at https://youtu.be/eEx1a pBAS9A. Accessed 7 May 2018.

19. GSD Harvard. 2017. Online video. Richard Sennett: The Open City. Available at https://www.youtu be.com/watch?v=7PoRrVqJ-FQ. Accessed 21 May 2018.

20. Harvey, D. 2002. Spaces of hopes. Edinburgh: University of Edinburgh Press.

21. Harvey, D., and A. Herod. 2009. Social justice and the city. Athens, GA: University of Georgia Press.

22. Hasegawa, G. 2011. Thinking, making architecture, living. Tokyo, JP: Lixil.

23. Hayles, K.N. 1999. How we became post-human: Virtual bodies in cybernetics, literature, and informatics. Chicago, IL: University of Chicago Press.

24. Her. 2013. Film. Directed by Spike Jonze. USA: Annapurna Pictures, 126 mins.

25. Jacobs, J. 1961. The death and the life of the great American cities. New York, NY: Random House.

26. Jacobs, J. 1969. The economy of cities. New York, NY: Random House. 
27. Johnny, Mnemonic. 1995. Film. Directed by Robert Longo. USA-Canada: Alliance Communications, 96 mins.

28. Kostof, S. 1991. The city shaped. London: Thames and Hudson.

29. Kostof, S. 1992. The city assembled. London: Thames and Hudson.

30. Landi, D. 2017. Cities “on the Run”. In Studio magazine 12. Milan, IT: Rrc Studio.

31. Lefebvre, H. 1991. Critique of everyday life: Introduction. London: Verso.

32. Lefebvre, H. 1992. The production of space. Oxford: Wiley-Blackwell.

33. Lefebvre, H. 1996. Writing on cities. Oxford: Wiley-Blackwell.

34. Lefebvre, H. 2003. The urban revolution. Minneapolis, MN: University of Minnesota Press.

35. Lefebvre, H. 2004. Rhythmanalysis: Space, time and everyday life. London: Continuum.

36. Lefebvre, H. 2014. Toward an architecture of enjoyment. Minneapolis, MN: University of Minnesota Press.

37. Lo and Behold, Reveries of the Connected World. 2016. Film. Directed by Werner Herzog. USA: NetScout, 98 mins.

38. Lynch, K. 1960. The image of the city. Boston, MA: MIT Press.

39. Maldonado, T. 1992. La speranza progettuale. Turin, IT: Giulio Einaudi Editore.

40. Markus, T.A. 1993. Building and power. London: Routledge.

41. Matsuda, K. 2009. Online video. Augmented (Hyper) Reality: Domestic Robocop. Available at: https:// vimeo.com/8569187. Accessed 18 Dec 2017.

42. Matsuda, K. 2013. Online video. Hyper-Reality Kickstarter: Update 3, Day 25. Available at: https:// vimeo.com/80841837. Accessed 18 Dec 2017.

43. Matsuda, K. 2013. Online video. Kickstarter - Hyper-Reality: A New Vision of the Future. Available at: https://vimeo.com/78557705. Accessed 18 Dec 2017.

44. Matsuda, K. 2016. Online video. Hyper-Reality. Available at: https://vimeo.com/166807261. Accessed 18 Dec 2017.

45. Matsuda, K. 2017. Keichi Matsuda. Critical Design. Available at: http://km.cx/projects. Accessed 18 Dec 2017.

46. Minority Report. 2002. Directed by Steven Spielberg. USA: Twentieth Century Fox, DreamWorks SKG, 146 mins.

47. Mitchell, W.J. 1996. City of bits. Boston, MA: MIT Press.

48. Mitchell, W.J. 1999. E-topia: Urban life, Jim-but not as we know it. Boston, MA: MIT Press.

49. Mitchell, W.J. 2004. Me++: The cyborg self and the networked city. Boston, MA: MIT Press.

50. Mustafavi, M. 2017. The ethics of the urban: The city and the space of the political. Zurich, CH: Lars Muller Publishers.

51. Nirvana. 1997. Film. Directed by Gabriele Salvatores. Italy: Vittorio Cecchi Gori, 111 mins.

52. OECD. 2017. The next production revolution. Paris: OEDC Publishing.

53. Orwell, G. 2008. Nineteen eighty-four. London: Penguin Books.

54. Pallasmaa, J. 2009. The eyes of the skin: Architecture and the senses. Oxford: Wiley-Blackwell.

55. Rossi, A. 1982. The architecture of the city. Cambridge, MA: MIT Press.

56. Sci-Arc. 2016 Online video. Antoine Picon, Architecture Matter and Language in Digital Age. Available at: https://www.youtube.com/watch?v=BoiHW2Fuy0k\&t=193s. Accessed 25 May 2018.

57. Sennett, R. 1970. The use of disorder. New York, NY: W. W. Norton and Company.

58. Sennett, R. 1993. The conscience of the eye: The design and social life of cities. New York, NY: W. W. Norton and Company.

59. Sennett, R. 1994. Flesh and stone: The body and the city in western civilization. New York, NY: Norton Paperback.

60. Sennett, R. 2003. Respect: The formation of character in an age of inequalities. London: Penguin Book.

61. Sennett, R. 2004. The fall of pubic man. New York, NY: Penguin Books.

62. Sennett, R. 2012. Together: The rituals, pleasure and politics of cooperation. London: Penguin Book.

63. Sennett, R. 2018. Building and dwelling: Ethics of the city. London: Penguin Book.

64. Serres, M. 1985. The five senses. London: Bloomsbury Academic.

65. Sudjic, D. 2016. The language of cities. New York, NY: Penguin Books.

66. Tafuri, M. 1976. Architecture and utopia: Design and capitalist development. Boston, MA: MIT Press.

67. The Circle. 2017. Film. Directed by James Ponsoldt. USA: Image Nation Abu Dhabi, 110 mins.

68. The Zero Theorem. 2013. Film. Directed by Terry Gilliam. Romania-UK: Zero Theorem, MediaPro Studios, Voltage Pictures, The Zanuck Company, Zanuck Independent, 107 mins.

69. Venturi, R. 1972. Learning from Las Vegas. Boston, MA: MIT Press. 
70. Vesely, D. 2004. Architecture in the age of divided representation: The question of creativity in the shadow of production. Boston, MA: MIT Press.

71. Vitruvius. 1914. The ten books on architecture. Cambridge, MA: Harvard University Press.

72. Zamyatin, Y. 2007. We. London: Vintage.

\section{Affiliations}

\section{Davide Landi ${ }^{1}$}

1 School of Art and Design, Liverpool John Moores Univeristy, 2 Duckinfield Street, Liverpool L3 5RD, UK 